\title{
ARTIKELEN
}

THEMA-ARTIKEL

\section{Kritische bestuurskunde}

\section{Naar een reflexief perspectief op bestuur en beleid*}

\author{
Robert van Putten, Lars Dorren \& Willem Trommel
}

Gedurende de afgelopen veertig jaar heeft de Nederlandse bestuurskunde zich ontwikkeld tot een vakgebied dat vooral kennis produceert die ofwel een zeer specifieke wetenschappelijke doelgroep bedient, of op instrumentele wijze wil bijdragen aan het optimaliseren van de beleidspraktijk. Deze typen van kennis zijn waardevol, maar geven niet de inzichten die nodig zijn om de maatschappelijke uitdagingen van deze tijd te doorgronden of te beantwoorden. In dit artikel betogen we dat de bestuurskunde haar focus meer zou moeten toeleggen op het bestuderen van reflexieve kennis, ofwel kritische bestuurskunde. Aan de hand van de overige bijdragen in dit themanummer laten we zien wat de bijdrage van zo'n kritische bestuurskunde zou kunnen zijn. Het artikel toont aan dat kritische bestuurskunde zich altijd dicht op de beleidspraktijk bevindt, en als geen ander in staat is het publiek debat te voeden door het schetsen van alternatieve toekomsten.

\section{Een roep om verandering}

Enkele jaren geleden heeft de redactie van dit tijdschrift de bestuurskundige gemeenschap uitgedaagd tot zelfreflectie: waar staan we na ruim veertig jaar bestuurskunde en wat zijn belangrijke bestuurskundige thema's voor de nabije toekomst? De beschouwingen rond deze vragen zijn naderhand ook verschenen in de bundel 'Toekomst van de bestuurskunde' (Karré, Schillemans, Van der Steen, \& Van der Wal, 2017). De bundel laat zien hoe het vakgebied zich heeft verbreed en verdiept, en hoe nieuwe generaties aantreden en weer andere accenten leggen. In de slotbeschouwing op deze bestuurskundige zelfreflectie doet Schillemans (2017) een aantal treffende observaties: bestuurskundigen zijn vooral in de weer met het spanningsveld tussen wetenschappelijke prestige en methodologische verfijning enerzijds en maatschappelijke en beleidsmatige rele-

* R.J. van Putten MSc MA is promovendus aan de afdeling Bestuurswetenschappen en Politicologie, Vrije Universiteit Amsterdam.

L. Dorren MA MSc is promovendus aan de onderzoeksgroep Politics \& Public Governance, Universiteit Antwerpen.

Prof. dr. W.A. Trommel is hoogleraar Bestuur en beleid aan de afdeling Bestuurswetenschappen en Politicologie, Vrije Universiteit Amsterdam. 
vantie anderzijds. Dit laatste heeft bovendien een heel specifieke invulling gekregen: de bestuurskundige als adviseur, die heel meegaand en dienstbaar is aan overheden en hun beleidswensen en kennisvragen. Dat maakt het ruim veertig jaar oude vakgebied een uiterst brave discipline, aldus Schillemans.

De bestuurskunde heeft zich, anders gezegd, vooral toegelegd op de productie van wat Burawoy (2005) 'instrumentele kennis' noemt. Veel van wat er in de bestuurskunde aan kennis wordt geproduceerd, heeft als doel om bestaande praktijken met een technisch-rationele bril te optimaliseren en verfijnen. Tegelijkertijd heeft de bestuurskunde maar weinig geïnvesteerd in de ontwikkeling van wat Burawoy 'reflexieve kennis' noemt. Dit type kennis bevraagt juist de uitgangspunten van het vakgebied, onderzoekt de rol van publieke waarden in beleid en bevordert het democratisch gesprek daarover. Het gaat om kennis die niet primair dienstbaar is aan de overheid, maar de bestaande macht kritisch analyseert en indien nodig van goede alternatieven voorziet. Burawoy spreekt dan van 'kritische' en 'publieke' sociale wetenschap, waarbij de eerste volgens Burawoy een academisch publiek voor ogen heeft en de tweede een algemeen, niet-academisch publiek.

Schillemans (2017) vraagt zich hardop af of de bestuurskunde deze reflexieve kennis niet ten onrechte onbenut laat in een tijd van polarisatie, politisering en toename van soms irreële verwachtingen van juist ook de ambtelijke kant van de overheid. Een tijd waarin de nadruk juist veel vaker lijkt te liggen op de normatieve posities die aan het huidige bestuur van besturen ten grondslag liggen. Hij suggereert dan ook dat de bestuurskunde van deze reflexieve kennis, de kritische en publieke benaderingen, meer werk zou moeten maken om de kwaliteit van het vakgebied te verbeteren. Daarin vindt hij eminence grise Arthur Ringeling aan zijn zijde, die bijna gelijktijdig met zojuist genoemde bundel een eigen reflectie op het vakgebied publiceerde. Ringeling (2017) betoogt in 'Public Administration as a Study of the Public Sphere: A Normative View' ook dat het vakgebied te zeer dienstbaar aan de macht is geworden en een verengde focus op verbetering van beleid en management heeft ontwikkeld. Daartegenover vraagt hij juist weer aandacht voor de normatieve uitgangspunten en ambities van het vakgebied, vanuit het besef dat bestuurskunde een taak heeft voor de publieke samenleving als zodanig, met de rechtsstaat als normatieve kern.

Uit de bestuurskundige zelfreflectie komt dus de roep om heroriëntatie omtrent de koers en attitude van het vakgebied naar voren. Die handschoen wordt in dit themanummer opgepakt. Of beter gezegd: die handschoen heeft een groeiende groep van bestuurskundigen van allerlei Nederlandse en Vlaamse universiteiten al vrij snel na deze diagnosen opgepakt door de organisatie van een panel 'Explorations in Public and Critical Public Administration' op de jaarlijkse NIG-conferentie in 2018, gevolgd door de oprichting van een NIG-Colloquium 'Critical and Interpretive Public Administration' in 2019. Dit panel en colloquium tonen een diversiteit aan tradities in kritische bestuurskunde en een diversiteit aan concrete vraagstukken en toepassingen. Het zijn de levenstekens van een vitale en zich ontwikkelende stroming in de bestuurskunde. Dit themanummer bouwt voort op 
het NIG-panel uit 2018 en heeft als doel de noodzaak, mogelijkheid en veelzijdigheid van een meer kritische bestuurskunde te verkennen. Het wil de maatschappelijke relevantie, theoretische bronnen en bestuurskundige toepassingsmogelijkheden van kritische benaderingen voor het voetlicht brengen.

\section{De wereld van kritische bestuurskunde}

De goede verstaander merkt ondertussen op dat wij nu van 'kritische bestuurskunde' spreken, in plaats van Burawoy's (2005) onderscheid tussen 'kritische' en 'publieke' wetenschap aan te houden. Dat is niet omdat we ons in dit themanummer tot een van de twee willen beperken, maar een onderkenning van het feit dat we het onderscheid tussen kritisch en publiek als beperkend ervaren. Burawoy is er zelf uiteindelijk op gespitst om zijn eigen vakgebied, de sociologie, weer meer tot een publieke wetenschap te maken (net als Willem Schinkel dat in Nederland poogt). Maar het gevolg daarvan is dat Burawoy 'kritische' sociale wetenschap slechts de rol van het geweten van het vakgebied toebedeelt (en waarin Schillemans (2017) wat al te gemakkelijk in meegaat). Voor de bestuurskunde, een vakgebied dat inherent dicht bij praktijk en publiek staat, is een dergelijke tweedeling tussen academisch en niet-academisch inherent vreemd. Een kritische benadering heeft volgens ons niet alleen maar de uitgangspunten van het vakgebied als object van analyse, maar juist ook de politieke realiteit en de beleidspraktijk (zie bijvoorbeeld Box, 2005).

Die beleidspraktijk is immers waar politiek handen en voeten krijgt, waar bijvoorbeeld een vrijheidsopvatting wordt vertaald in het aanleggen van extra rijstroken, en interpretaties van een idee over eigen verantwoordelijkheid gaan bepalen of iemand wel of niet in aanmerking komt voor een toeslag. Het is de beleidspraktijk waar waardenconflicten materialiseren en we erachter komen waar 'het democratisch gesprek' concreet over gaat. De praktijk is de plek waar men betekenis moet geven aan neutraal ogende feiten en cijfers en waar men gevraagd wordt te handelen, ondanks onzekerheden. Het blootleggen van de waardevragen van de beleidspraktijk maakt kritische bestuurskunde bij uitstek ook een publieke aangelegenheid, relevant voor zowel de praktijk waar zij over schrijft als het breder maatschappelijk debat. Al kan een kritisch-bestuurskundige analyse meer of minder zijn geschreven voor een breed publiek, ze heeft wel steeds een publiek belang voor ogen. Dat zal verder ook blijken in de verschillende bijdragen van dit themanummer.

Hiermee is nog niets gezegd over de inhoud van kritische bestuurskunde en die inhoud laat zich ook niet zomaar vangen in enkele typeringen. Dat komt omdat het geen subdomein binnen de bestuurskundige theorie (zoals New Public Management en New Public Governance) of de beleidspraktijk betreft (zoals onderwijsbeleid, gezondheidszorg of lokaal bestuur). Kritische bestuurskunde is eerder een onderzoeksbenadering die elk van deze thema's op radicaal eigen wijze benadert. Bovendien zijn tal van kritische scholen te onderscheiden en die scholen kunnen ook weer sterk met elkaar botsen (Thomson, 2017). Bij het samen- 
stellen van dit themanummer hebben we niet op voorhand voor een definitie of specifieke school gekozen, maar willen we juist de diversiteit en spanningen tussen de verschillende kritische tradities beproeven en toegankelijk maken voor de Nederlandse bestuurskunde en beleidspraktijk. De inzet is om het gesprek te starten en daarbij te onderzoeken welke tradities in kritische bestuurskunde vruchtbaar zijn en waarom. Kritische bestuurskunde verwijst dus - voorlopig naar een veelvoud aan kritische tradities, naar een breed palet aan auteurs, concepten en invalshoeken waarmee reflexieve kennis voor bestuur en beleid kan worden ontwikkeld.

Die breedte laat zich, heel grofmazig, als volgt schetsen. Historisch gezien laat de zogenoemde 'Frankfurter Schule' zich begrijpen als begin van wat we hier 'kritische theorie' noemen, met als founding fathers Horkheimer en Adorno. Zij maakten het onderscheid tussen 'traditionele' (positivistische) theorie en 'kritische' theorie die de schijnbaar neutrale traditionele theorie wijst op het ideologische karakter van haar grondbeginselen. Vanaf de jaren dertig van de twintigste eeuw hebben zij (geïnspireerd door het werk van Karl Marx) aan kritische maatschappijanalyse gedaan en daartoe een instituut gebouwd, waar later ook auteurs als Marcuse, Habermas en Honneth uit voortgekomen zijn (zie Hoefnagels, 1974 voor een Nederlandstalige introductie). Vervolgens zijn naast en ook in polemiek met deze vaak als massief-systemisch en utopisch begrepen Frankfurter Schule meer postmoderne vormen van kritische theorie ontwikkeld (zoals postkoloniale theorie en kritisch feminisme, zie Thompson, 2017), waarvan het werk van de Franse denker Michel Foucault het meest bekend is. Terwijl in deze meer postmoderne scholen deconstructie van machtsverhoudingen alle aandacht lijkt op te eisen, zijn aan de randen ervan weer nieuwe kritische scholen opgekomen die juist ook weer aandacht hebben voor het reconstructieve, opbouwende, element van kritische theorie. Zo blijkt het pragmatisme een bron voor kritische analyse van beleid, bestuur en politiek (Forester, 1993; Zanetti, 1997), evenals premoderne denkers als Aristoteles (zie Flyvbjerg, 2001).

\section{Het palet dat dit themanummer bestrijkt}

Zo breed als de wereld van de kritische bestuurskunde is, zo breed is ook het voorliggende themanummer. De veelzijdigheid en reikwijdte van de verschillende kritische scholen wordt hier bovendien ook min of meer in historische lijn gepresenteerd, zonder daarin overigens de ambitie te hebben uitputtend te zijn. Daarbij heeft de redactie gekozen voor een serie korte essays, zodat we binnen het bestek van een themanummer in staat zijn om een breed palet aan theoretische perspectieven en toepassingen te presenteren.

Het themanummer opent met de oudste en meest prominente scholen in kritische bestuurskunde. Ringo Ossewaarde presenteert in zijn essay de vroege Frankfurter Schule, waarin hij grondlijnen van het denken van Horkheimer, Adorno en Marcuse schetst en verbindt aan de bestuurskunde en de actuele thematiek van 'algoritmisch bestuur'. Daarna demonstreert Shivant Jhagroe de actualiteit van 
Michel Foucault en diens begrip van 'governmentaliteit'. Op basis van een uitleg van diens conceptueel raamwerk analyseert hij vervolgens het debat over klimaatmaatregelen en het karakter van hedendaags klimaatbeleid.

$\mathrm{Na}$ de bespreking van deze twee grote scholen staan drie meer recente en deels nog ontluikende vormen van kritische theorie centraal. Yvonne La Grouw laat zien hoe Aristoteles' begrip van praktische wijsheid (phronesis), zoals dat vooral ook door de al genoemde Flyvbjerg in de bestuurskunde opnieuw onder de aandacht is gebracht, potentie bezit voor een kritische bestuurskunde die maatschappelijk relevant wil zijn en dicht op de praktijk wil zitten. Het essay van Tamara Metze heeft daar veel verwantschap mee. $\mathrm{Zij}$ herneemt de notie van het 'kritisch pragmatisme' dat ook bij Forester te vinden is en laat zien hoe kritisch en pragmatisch denken geen tegengestelden hoeven te zijn, maar elkaar juist kunnen versterken. Ze demonstreert dat door een hypothetische uitwerking van processen voor een rechtvaardig energiebeleid. Hans Joosse presenteert de zogenoemde complexiteitstheorie als een vorm van kritische bestuurskunde. Hij contrasteert dat met het simplificerende machinedenken dat de werkelijkheid 'eendimensionaal maakt' (in termen van het essay van Ossewaarde). Complexiteitstheorie kan nieuw handelingsperspectief bieden dat daaraan ontsnapt en meer recht doet aan de realiteit van het bestaan.

Deze vijf bijdragen gaan over kritisch bestuurskundig onderzoek, maar het is ook belangrijk om de brug te slaan naar het bestuurskundig onderwijs. Niet alleen ligt daar een groot deel van de werkzaamheden van het bestuurskundig vakgebied, maar daar ligt ook een grote kans voor de verdere ontwikkeling van kritisch bestuurskundigen die hun weg vinden naar de praktijk van beleid, politiek en overheidsbestuur. De vraag waar dit themanummer dan ook mee afsluit, is in hoeverre bestuurskundig onderwijs kritisch is, en hoe dergelijk onderwijs eruit zou kunnen zien. Dat bespreken Mark van Ostaijen en Shivant Jhagroe in een pleidooi voor 'productieve subversiviteit'.

\section{Zicht op een andere toekomst}

Zonder de contradicties en spanningen tussen de verschillende vormen van kritische bestuurskunde alweer te willen verzoenen, worden door deze essays heen een aantal gedeelde patronen zichtbaar. Ten eerste wordt duidelijk dat kritische scholen niet ver afstaan van de werkelijkheid, de brug naar de praktijk van beleid en politiek hoeft niet apart te worden geslagen. Kritische reflecties gaan onmiddellijk over actuele vraagstukken: algoritmen, infrastructuur, klimaat en energie. Bovendien biedt de kritische bestuurskunde inzichten die essentieel zijn voor het doorgronden van deze vraagstukken door bijvoorbeeld te laten zien hoe we morele beslissingen overlaten aan algoritmen, en hoe nieuw energiebeleid ook een verdelingsvraagstuk is. Anders gezegd, kritische bestuurskunde komt op uit betrokkenheid bij en zorg over de politiek-bestuurlijke realiteit. Na decennia van wat Trommel (2018) 'neoliberale drift' noemt, waarbij openbaar bestuur werd gekenmerkt door trends als New Public Management-denken en evidence-based, 
'rationele' beleidsprocessen maken, en de daaropvolgende 'verkrampte' populistische roep (Trommel, ibid.) om een terugkeer naar conservatieve waarden en een lokaler perspectief, lijken veel maatschappelijke debatten op slot te zitten, of getekend te worden door grote verdeeldheid. Terwijl zich grote maatschappelijke transformaties aftekenen - de mondialisering van economie, de opmars van artificiële intelligentie, culturele fragmentatie, de roep om een ander klimaatbeleid ontbreekt het de bestuurskunde aan inspirerende normatieve reflectie hierop. Kritische bestuurskunde beoogt hier een aanjagende rol te vervullen.

Ten tweede draait kritische bestuurskunde niet slechts om het van een veilige afstand leveren van kritiek. Kritische bestuurskunde is meer dan 'speaking truth to power'. Ja, er worden machtsstructuren geïdentificeerd en geproblematiseerd, maar de blik is steeds toekomstgericht en concreet. Steeds weer benoemen de auteurs dat in de kritische analyse alternatieve maatschappelijke en bestuurlijke mogelijkheden oplichten. Bij het identificeren van praktijken van 'instrumentalisering', 'simplificatie' of 'eendimensionaliteit' dienen zich ook steeds momenten en handelingsperspectieven aan die daar iets tegenover stellen. Die handelingsperspectieven worden in dit themanummer ook daadwerkelijk gedemonstreerd. Dat maakt kritische theorie geen negatieve bezigheid, maar hoopvol en constructief.

De handelingsperspectieven die kritische bestuurskunde in al haar diversiteit aanbiedt, zijn wel van een andere aard dan wat hiervoor 'instrumentele' bestuurskunde is genoemd. Niet technisch-rationele verbetering of vooruitgang staat centraal, maar de articulatie van waarden zoals het leven van de geest, vrijheid, democratie en rechtvaardigheid. Dat zijn heel andere bestuurskundige toekomstbeelden dan men doorgaans aantreft. Men zou zich terecht kunnen afvragen of de kritische bestuurskunde met haar normatieve focus geen vorm van als wetenschap verklede partijpolitiek is. De inzet is echter niet de feiten voor het gebod te vervangen. Daartussen ligt het perspectief van het 'können', van de alternatieve 'mogelijkheden' die als stem in het publieke gesprek worden ingebracht zonder daarin dwingend te willen zijn (Boutellier, 2015). Daarin gaat het niet om verdediging van politieke of ethische standpunten door deze aan te kleden met wetenschappelijke theorie en empirische feiten, maar om beredeneerde sociaalwetenschappelijke diagnoses en handelingsperspectieven.

Ter afronding. Dit themanummer doet een aanzet om een andere toekomst van de bestuurskunde te verbeelden. Daarmee is niet gezegd dat die toekomst ook werkelijkheid wordt. Dat vergt radicale keuzes en een serieuze heroriëntatie op de vraag waartoe de bestuurskunde op aarde is. We pretenderen niet dat de bijdragen aan dit themanummer sluitende antwoorden bieden. Wel hopen we dat inzichtelijk gemaakt wordt dat in kritische tradities iets te halen valt dat onze samenleving hard nodig heeft en de bestuurskunde binnen het geheel van beleidsgeoriënteerde wetenschappen weer een heel eigen karakter geeft. Ook hopen we dat dit themanummer op zijn minst aanzetten doet voor een goed en langer gesprek binnen de bestuurskunde over haar aard en bijdragen aan de samenleving. 


\section{Literatuur}

Boutellier, J.C.J. (2015). Het seculiere experiment: Hoe we van God los gingen samenleven. Amsterdam: Boom.

Box, R.C. (2005). Critical social theory in public administration. New York/London: M.E. Sharpe.

Burawoy, M. (2005). For public sociology. American Sociological Review, 70(1), 4-28.

Flyvbjerg, B. (2001). Making social science matter: Why social inquiry fails and how it can succeed again. Cambridge: Cambridge University Press.

Forester, J. (1993). Critical theory, public policy and planning practice: Toward a critical pragmatism. Albany: State University of New York Press.

Hoefnagels, H. (1974). Kritische sociologie: Inleiding tot het sociologisch denken der 'Frankfurter Schule'. Alphen aan den Rijn: Samsom Uitgeverij.

Karré, P.M., Schillemans, T., Steen, M. van der, \& Wal, Z. van der. (2017). Toekomst van de bestuurskunde. Den Haag: Boom Bestuurskunde.

Ringeling, A. (2017). Public administration as a study of the public sphere: A normative view. The Hague: Eleven International Publishing.

Schillemans, T. (2017). Staat van de bestuurskundes: Uitdagingen en kansen op vier belangrijke velden. In P.M. Karré, T. Schillemans, M. van der Steen, \& Z. van der Wal (red.), Toekomst van de bestuurskunde (pp. 129-143). Den Haag: Boom bestuurskunde.

Thompson, M.J. (Ed.). (2017). The Palgrave handbook of critical theory. New York: Palgrave/ Macmillan.

Trommel, W.A. (2018). Veerkrachtig bestuur: Voorbij neoliberale drift en populistische kramp. Den Haag: Boom bestuurskunde.

Zanetti, L.A. (1997). Advancing praxis: Connecting critical theory with practice in public administration. American Review of Public Administration, 27(2), 145-167. 